\title{
Nanostructuring Methods for Enhancing Light Absorption Rate of Si-Based Photovoltaic Devices: A Review
}

\author{
Soonwook Hong', Jiwoong Bae', Bongjun Koo', lkwhang Chang', Gu Young Cho², \\ Young-Beom Kim",, Suk Won Cha', and Fritz B. Prinz ${ }^{3}$ \\ 1 Department of Mechanical Engineering. Hanyang University, Seongdong-gu, 222 Wangsimni-ro, Seoul 133-791, South Korea \\ 2 Department of Mechanical and Aerospace Engineering, Seoul National University, Gwanak-ro 1, Gwanak-gu, Seoul 151-744, South Korea \\ 3 Department of Mechanical Engineering, Stanford University, Stanford, CA 94305, USA \\ \# Corresponding Authors / E-mail: ybkim@hanyang.ac.kr, TEL: +82-2-2220-0544, FAX: +82-2-2220-2299:
}

KEYWORDS: Photovoltaic device, Light absorption, Vapor-liquid-solid, Solution-liquid-solid, Reactive ion etching, Metal assisted chemical etching

\begin{abstract}
In recent years, there has been growing consideration of renewable energy especially photovoltaic devices. A silicon (Si) based solar cell is the most popularly and frequently considered among the photovoltaic devices, but its bulk thickness issue lowers the performance and hinders widespread application due to the material cost. Also, this thick nature causes difference in length between minority carrier diffusion and sufficient light absorption. To mitigate the issues there have been many recent studies on Si photovoltaic devices adopting nanostructuring strategies to enhance the performance. Therefore, we report two different approaches on recent nanostructuring techniques for photovoltaic devices; bottom-up and top-down processes, which are composed of vapor-liquid-solid, solution-liquid-solid, reactive ion etching with Langmuir Blodgett and metal assisted chemical etching. Those fabrication processes enable the fabrication of nanostructures with a highly ordered and alignment structures leading to enhance the light absorption and have an appropriate thickness of Si substrate regressing Auger recombination. The fabricated nanowire and nanocone array structures outperform existing results with light absorption exceeding $90 \%$.
\end{abstract}

\section{Introduction}

Many studies have been focused on energy conversion devices utilizing renewable energy sources such as hydrogen, solar, geothermal, wind, and biofuels. ${ }^{1-5}$ Among those renewable energy systems, photovoltaics (PV) may be the most attractive solution for the replacement of fossil fuel due to zero emissions, environmentfriendliness and infinite reserves. Since first discovery of the photovoltaic effects, less research and trials for the commercialization of the PV has been conducted until the appearance of the silicon (Si) based solar cell. ${ }^{6,7}$ Though the initially invented Si based PV had a only $\sim 4 \%$ of efficiency of converting sun light into electricity, by the help of continual research efforts, the efficiency has significantly increased up to near the theoretical value of the single junction Si-PV. ${ }^{7,8}$

Indeed, despite discordance of band gap energy between the $\mathrm{Si}$ $(1.1 \mathrm{eV})$ and the optimal value $(1.4 \mathrm{eV})$ for single junction solar cell, $\mathrm{Si}$ has been considered as a promising material for $\mathrm{PV}$, particularly crystalline $\mathrm{Si}-\mathrm{PV} .{ }^{9,10}$ The $\mathrm{Si}$ is second abundant element in earth and has non-toxicity, enabling to wide utilize in PV industry. It is also attractive point for using Si-PV that the surface of Si substrate can be easily passivated by thermal oxidation for prevention of surface recombination. However, the crystalline Si-PV should have $10 \sim 1000 \mu \mathrm{m}$ of the thickness for absorption of photons in various wavelengths due to its indirect band gap, and therefore, electron and hole pairs are readily recombined via Auger recombination in surface of Si-PV, as shown in Fig. 1(a). ${ }^{1,11,12}$ This bulky thickness of Si significantly drives up the fabrication cost of Si-PV devices. Also, it accounts for $\sim 40 \%$ of the total fabrication cost and this hinders growth of the solar cell commercialization for industrial use. ${ }^{13}$ Therefore, many strategies have been conducted to overcome the fabrication cost issue in silicon based solar cell such as using other materials having direct band gap for example cadmium telluride (CdTe). Especially, cadmium telluride (CdTe), gallium arsenide (GaAs), indium phosphide ( $\mathrm{InP})$, copper indium gallium selenide (CIGS) and their alloys and ternaries/ 
quaternaries compounds have been considered as the most promising materials for PV. However, these materials are much expensive and phase diagram is also quite complicate to fabricate in a large scale production. Therefore, the development of the doping techniques for hydrogenated amorphous silicon (a-Si:H) has received great attention since it has higher absorptivity than bulky Si based solar cell by help of thin film process with conventional thin film deposition techniques. $^{14,15}$ This high absorption of light in a varied spectrum resulted from the high structural disorder in the material allowing all optical transition, while the disorder simultaneously served as core part of recombination which highly reduces the carrier lifetime. ${ }^{10,14}$ However, during the deposition of a-Si: $\mathrm{H}, 10 \%$ of the hydrogen incorporated greatly reduced the density of disorder, so it is considered that a-Si:H is the most suitable materials itself for substrate of thin film solar cells as well as substrate for nanostructure. ${ }^{14}$ Although a-Si:H solar cells are subject to the Staebler-Wronski effect, which is caused by light-induced degradation related to a creation of defect acting as non-radiative recombination centers, it is also partially overcome by reducing the thickness of the a-Si:H layer in solar cells. ${ }^{1,14,16}$

However, as in the case of the a-Si:H thin film solar cells, it has no chance to have less than $1 \mu \mathrm{m}$ of thickness in order to absorb sufficient light spectrum unlike the minority carrier diffusion length has the typical length of the $300 \mathrm{~nm} .{ }^{17}$ This difference of the length for sufficient light absorption and diffusion length causes significant reduction of the Si-PV power generation due to a lack of light absorption and the loss of the carrier collection in the electrodes. ${ }^{17,18}$ For this reason, many researchers try to narrow this gap and then nanostructure (i.e. nanorod, nanowire, nanocone, and nanohole) is considered as a solution. This strategy is

(a)

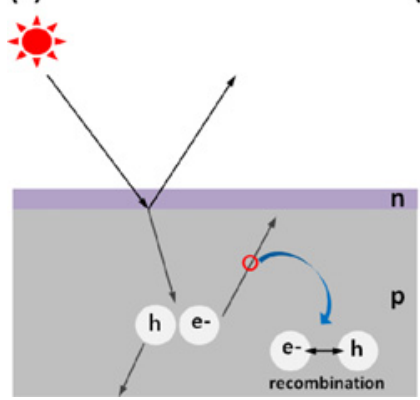

(b)

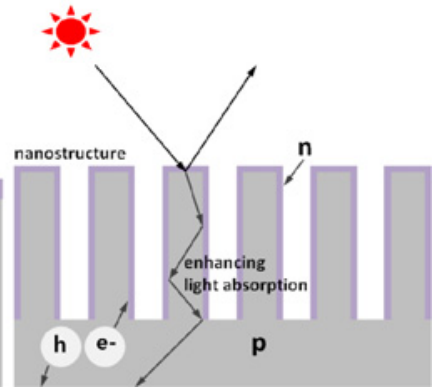

Fig. 1 (a) The conventional bulk Si-PV leading to Auger recombination in surface and have relatively long path of diffusion length, (b) The SiPV with nanostructure have relatively short path of diffusion length and enhanced light absorption in wide region of wavelength

(a)

(b)
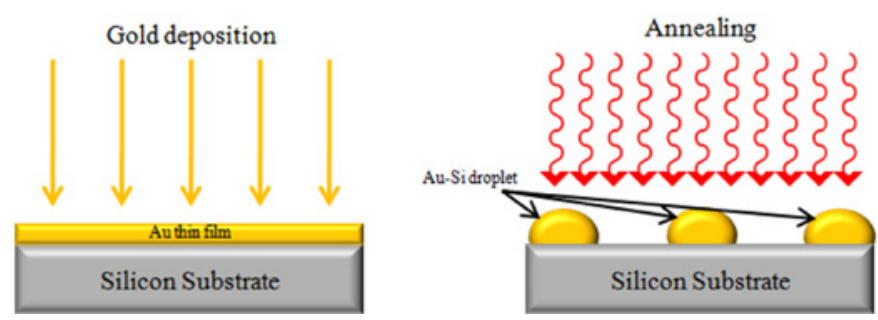

mostly helpful to enhance light absorption in various wavelengths and increase the diffusion length of photons in Si-PV. ${ }^{19,20}$ As shown in Fig. 1(b), the nanowire, commonly has $1 \sim 50 \mu \mathrm{m}$ of height and $10 \sim 500 \mathrm{~nm}$ of diameter, allows to the sufficient thickness of the light absorption for thin film Si-PV, while simultaneously offering a relatively short path of the carrier collection which means the efficient collection of carrier with short minority carrier diffusion length. ${ }^{18}$ In addition, compared to the technique achieving more light absorption for conventional planar Si-PV, thin film Si-PV with nanostructure has more advantages than antireflection coating (ARC) which is only able to decrease the reflection with a specific incident angel of the sun light and wavelength. ${ }^{17}$

In this paper, we report recent fabrication process of thin film Si-PV with one-dimensional nanostructures specialized in enhancing light absorption. Among the nanostructures, nanowire and nanocone are the most considered structures due to highly ordered arrays leading to enhanced light absorption.

\section{Fabrication of Nanostructures}

In general, fabrication approaches can be divided into two on nanostructures for thin film Si-PV: deposition (bottom-up) and etching (top-down) methods. The thin film Si-PV strongly requires nanostructured scattering part using nanowires, nanorods, and nanocones. To fabricate the nanostructures for Si-PV, we therefore discuss the conventional fabrication process such as vapor-liquid-solid (VLS), solution-liquid-solid (SLS), metal assisted chemical etching, and reactive ion etching.

\subsection{Bottom-Up Method}

Lieber et al. reported a new method based on bottom-up approach for silicon nanowire synthesis. ${ }^{21-25}$ VLS has been introduced and developed to combine with high techniques: annealing in reactive atmosphere, laser ablation and evaporation. ${ }^{26-32}$ These techniques can generate nanoscale catalytic droplets with precise size control, high yielding rate, and purity.

The VLS process usually requires a thin gold film which is deposited on Si substrate via physical vapor deposition technique. The size and density of the Si nanowires are defined by the density and size of Au nanoparticles that can be controlled by the sputtering conditions and the thickness of the Au film. As shown in Fig. 2, VLS process has used about 1 10 nm thickness of Au film which is deposited by sputtering or evaporation. Then, thermal annealing process of the

Fig. 2 Schematic of Si nanowire growth process, (a) Au thin film is deposited on substrate by PVD, (b) Au-Si droplets are by thermal annealing and (c) Si nanowires grow from the reaction of $\mathrm{SiCl}_{4}$ and $\mathrm{H}_{2}$ vapor Phases 
deposited $\mathrm{Au}$ film creates Au-Si alloy droplets which have a lower melting temperature compared to each composition material. Therefore, $\mathrm{Si}-\mathrm{Au}$ alloy droplet can form a liquid type when the temperature is higher than the eutectic point $\left(363^{\circ} \mathrm{C}\right) . \mathrm{SiCl}_{4}$ and hydrogen vapor adsorbs onto the Au-Si alloy liquid surface and react gaseous mixture reaction $\left(\mathrm{SiCl}_{4}+2 \mathrm{H}_{2} \rightarrow \mathrm{Si}+4 \mathrm{HCl}\right)$ with catalytic assistance. As a result of the reaction, $\mathrm{Si}$ and hydrogen chloride are created and $\mathrm{Si}$ diffuses into $\mathrm{Au}-\mathrm{Si}$ alloy droplet. Subsequently, one dimensional crystalline nanowire is grown by a liquid metal alloy droplet. Si atoms are nucleated at the liquid-solid interface which leads to axial crystal growth by $\mathrm{Si}$ supersaturated liquid alloy droplet. Then, Si nucleation raises a droplet on the surface to promote nanowire growth. ${ }^{33-40}$

The solution-liquid-solid (SLS) growth mechanism shows similarities with the VLS process. Buhro et al. developed SLS method for synthesis of nanowire at a relatively lower temperature than the VLS method. Unlike the VLS method, SLS can create metal nanowires and lower the fabrication cost even in a large scale production. Moreover, SLS facilitates using metal catalyst with a low melting temperature, and the desired material can be created by decomposition of organometallic precursors in solution.

The production principle of Si nanowire using SLS method takes place as follows: metal catalyst $(\mathrm{Au})$ and silicon precursor such as diphenylsilane are distributed with hexane when heated and pressurized above the critical point. Then, uniformly distributed alkanethiol-capped $\mathrm{Au}$ single crystals take on nucleation sites for Si nanowire growth. When the concentration of Au is higher than Si over $18.6 \mathrm{~mol} \%$ at the temperature of eutectic point, $\mathrm{Au}$ is formed in an alloy phase with the solid $\mathrm{Si}$ in an equilibrium state. As a result, $\mathrm{Si}$ atoms are melted in the $\mathrm{Au}$ nanocrystals until the supersaturation, and uniform nanowire is formed by Si protruding from the Au-Si alloy particles. ${ }^{41,42}$

\subsection{Top-Down Method}

The lithography uses close-packed nano spheres as a masking structure which allows it to fabricate various sizes of nanopillars and cones with controllable spacing. ${ }^{43-44}$ Although spin coating method has been widely used, it provides relatively poor coverage and is difficult to create a closepacked monolayer on the desired substrate. Since the Langmuir Blodgett (LB) method provides precise control to form the close-packed monolayer of nanoscale particles in a relatively large area, the LB method has been used for the fabrication of a close-packed monolayer of spherical nano particles. The fabrication process of LB is described in Fig. 3. The
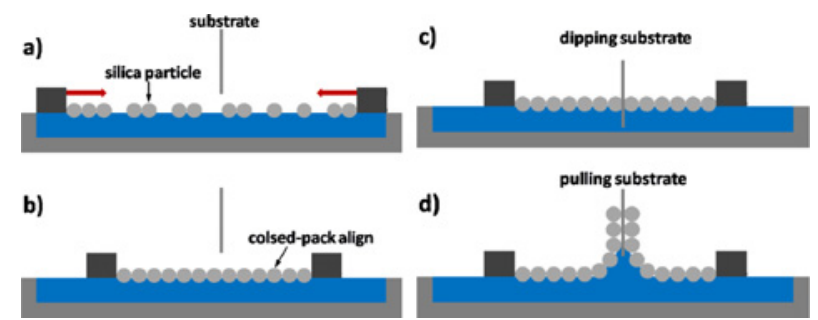

Fig. 3 The process of LB of (a) the dispersed silica particles are randomly located, (b) the close-packed array of silica particles are obtained using bar, (c) the substrate are submerged in distilled water, (d) then silica particles are stuck on substrate retaining the closepacked array synthesized nanoscale silica particles are dispersed on the surface of distilled water in the trough. Then, using compression bars a close-packed monolayer of silica particles can be formed while measuring the surface tension. Sequentially, a desired substrate is submerged in distilled water and is pulled out at a constant speed.

Due to capillary force and convective flow as the water evaporates, the particles follow the substrate and form a close-packed monolayer. After the particle transfer using LB method, combinatorial (physical and chemical) etching steps are required to fabricate the nanostructures. Reactive ion etching (RIE) is one of the dry etching methods having precise controllability and selectivity. ${ }^{45}$ This etching method is assisted by plasma to ionize and dissociate the gas molecules to chemically reactive ions. Then, the substrate can be placed on the bottom electrode which is negatively charged. The reactive ions diffuse to the substrate by d.c. driven electric force and absorption occurs on the substrate. The ionic chemicals react with the substrate, then are desorbed. Since the chemical products resulting in the reaction are volatile, they can be removed after the reaction. Lastly, the desorbed products are then pumped out.

For the fabrication of silicon nanopilars or nanocones, fluorine based or chlorine based gases are used. For example, if $\mathrm{SF}_{6}$ gas is used, the plasma generates $\mathrm{F}^{+}, \mathrm{SF}^{5+}$ and $\mathrm{F}^{-}$. The radicals $\left(\mathrm{F}^{+}\right)$diffuse with d.c. biased condition, reacts with $\mathrm{Si}$ atoms during the absorption and reaction process, and then produces $\mathrm{SiF}_{4}$ which is volatile and allows it to be removed. The intensity of plasma influences the directionality of etching. Therefore, isotropic etching usually requires moderate RF power while anisotropic etching needs strong plasma density. ${ }^{46}$ Figure 4 shows the actual images of homemade silica particles on the silicon substrate deposited by LB method (Fig. 4(a)) and the nanocone structures having various shapes created by RIE method (Fig. 4(b) and (c)).

Recently, a number of researchers focused on LB method for solar cell fabrication to create a light absoprtion structure and layer. ${ }^{17,47}$ In some literature, LB and RIE were used for fabrication of nanopilar and nanocone arrays. As shown in Fig. 5, the process of making nanocone has several steps. First of all, the surface of the synthesized particles

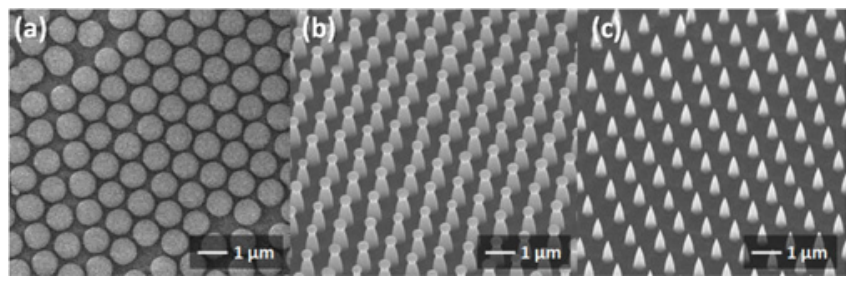

Fig. 4 FE-SEM images of (a) silica mask after RIE etching, (b) nanocones and silica particles, and (c) fabricated nanocones after HF etching of silica mask

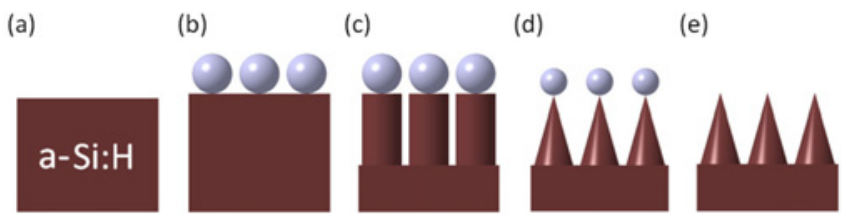

Fig. 5 The fabrication steps of nanocone structure. (a) On silicon wafer, (b) silica particles are dispersed via LB, and etched by selective and isotropic RIE, (c) The nanopillars can be made by anisotropic etching, (d) Then, the nanocones can be fabricated by isotropic RIE using $\mathrm{SF}_{6}$, (e) Lastly, the etch-mask can be removed by buffered oxide etching ${ }^{17}$ 
was modified with aminopropyl methyldiethoxysilnae to avoid agglomeration by giving positively charged amine groups and this gives repulsive force between each particle. Then, on a silicon wafer (Fig. 5(a)), close-packed monolayer of silica particles were created by LB method (Fig. 5(b)).

Silica particles have the diameter from few tens of nanometers to few microns. After the deposition of silica particles, selective and isotropic RIE was conducted to reduce the size of silica particles (Fig. 5(c)). In this step, the particle size can be controlled as well as the spacing between the particles. The RIE was performed with a gas mixture of $\mathrm{O}_{2}$ and $\mathrm{CHF}_{3}$. Then, the silicon wafer was etched to form nanopilars by $\mathrm{Cl}_{2}$ based anisotropic RIE etching which has selectivity to Si wafer (Fig. 5(d)). The height of the pilars can be controlled by adjusting the etching time of this RIE process. For the fabrication of nanocones, the anisotropic and isotropic etching was performed to make a sharp tip of nanocone arrays (Fig. 5. (e)). Due to the silica particles, there is a difference in gas diffusion rate at the top and the bottom of the pillars. That is the mechanism of fabricating the cone structures. The last step is removal of remaining the silica particles by buffered oxide etching.

Another method of the top-down nanostructuring is metal assisted chemical etching (MacEtching) which is intrinsically a wet etching method to fabricate Si nanostructures. Since Li et al. first adopted the noble metal (e.g. Au, Pt, Au/Pd alloy) as a catalyst in etching process MacEtching had growing concerns of etching techniques in the last decade. ${ }^{48}$ MacEtching has several advantages over other etching methods such as RIE, electrochemical etching, and anodic etching. Huang et al. well defined the merit of metal assisted chemical etching. ${ }^{49}$ It has a simple process, low fabrication cost, no limitation of the size of structures, the possibility to control the orientation of structures in a given substrate, flexibility of geometry in cross-sections, and fine crystalline quality.

MacEtching utilizes the characteristic of anisotropy in the etching process. The etching rate of $\mathrm{Si}$ which has the catalyst material on top is much faster than the etching rate of $\mathrm{Si}$ itself in the solution mixture of hydrogen peroxide and hydrofluoric acid. By using this characteristic, high aspect ratio nanowire or nanopillar structures can be achieved while the height of the structure is dependent on the etching time. Fig. 6 shows the schematic and the detailed process of metal assisted etching. Noble metal catalyst particles or a layer are deposited on the Si substrate by conventional metal deposition techniques. Then, the sample is put in the liquid solution of $\mathrm{H}_{2} \mathrm{O}_{2} / \mathrm{HF}$ mixture. Consequently, due to the catalytic reaction between the metal and the substrate, $\mathrm{Si}$ beneath the noble metal is etched much faster than $\mathrm{Si}$ without catalyst and the process keeps going on until the sample is taken out from the solution. (Fig. 6 (b)). The un-etched part of the Si substrate is the final nanostructures. In this process, a noble metal contact area is employed as partial cathodic areas in which occurs reduction of oxidants (e.g. $\mathrm{H}_{2} \mathrm{O}_{2}$ ).

Subsequently, the hole $\left(\mathrm{h}^{+}\right)$is generated as a byproduct of reduction and transferred to the interface between noble metal and Si substrate. Finally, the Si substrate is oxidized and transforms into an ionic state which is dissolved in an acid solution (e.g. HF). ${ }^{49,50}$

The reaction of MacEtching was presented by Chartier et al. who proposed mixed reaction..$^{51}$ The overall reaction is:

$$
\mathrm{Si}+\mathrm{H}_{2} \mathrm{O}_{2}+6 \mathrm{HF} \rightarrow \mathrm{nH}_{2} \mathrm{O}+\mathrm{H}_{2} \mathrm{SiF}_{6}+\mathrm{H}_{2}
$$

Where $\mathrm{n}$ is the number of holes in dissolved $\mathrm{Si}$ atom with cathodic and anodic reaction.

cathodic reaction: $\mathrm{H}_{2} \mathrm{O}_{2}+2 \mathrm{H}^{+} \rightarrow 2 \mathrm{H}_{2} \mathrm{O}+2 \mathrm{~h}^{+}$

anodic reaction: $\mathrm{Si}+6 \mathrm{HF}+\mathrm{nh}^{+} \rightarrow \mathrm{H}_{2} \mathrm{SiF}_{6}+\mathrm{nH}^{+}+\mathrm{H}_{2}$

One of the main features of the fabrication methods is that the capability of creating ordered nanostructures and controllability of the geometry such as the size or diameter, and spacing between fabricated nanostructures. It can be decided by the pattern of deposited noble metal particles or structure of the metal film created on the Si substrate. There are several methods for making patterns or local arrays on $\mathrm{Si}$ substrates. The most highly ordered arrays are obtained by templatebased masking method such as self-assembly of a monolayer using polystyrene (PS) spherical particles. Huang et al. firstly adopted the PS spheres as a masking material and created noble metal film structure on the Si substrate. Detailed process of this method is well presented in Huang's early report. ${ }^{52}$ They created a close-packed monolayer of PS spheres and gave some spacing between the spheres by dry etching technique. By using a thermal evaporation, the highly ordered honey comb pattern of a noble metal film was deposited through the spacing between the PS spheres. After removing the PS spheres, MacEtching was performed and the patterned noble metal sank in vertically remaining the un-etched Si substrate as a nanowire array. Another report by Huang et al. concerns with template-based etching method using anodic aluminum oxide (AAO) as a mask as well as polystyrene composite. ${ }^{53}$

AAO membrane/polystyrene composite was located on $\mathrm{Si}$ substrate and then polystyrene which served as a stabilizer was removed through the oxygen plasma. Subsequently, Si substrate was patterned in hexagonal geometry via RIE process and RCA solution which able to remove AAO from the patterned Si substrate. By using sputtering, the noble metal was deposited as a catalyst, then, vertically aligned $\mathrm{Si}$ nanowires were obtained through the metal assisted chemical etching.

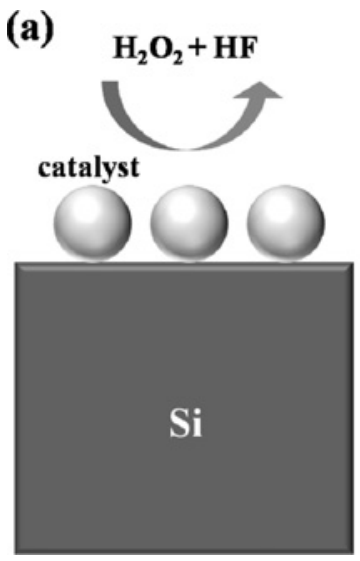

(b)

Fig. 6 The principle of metal assisted chemical etching, (a) catalyst is deposited on the substrate then $\mathrm{H}_{2} \mathrm{O}_{2} / \mathrm{HF}$ gases are applied, (b) substrate beneath the catalyst contacted area is etched into vertically and remain substrate exists as a nanostructure ${ }^{64}$ 


\section{Result Structures and Enhanced Absorption Rate}

\subsection{Nanowire Structures (Bottom-Up Method)}

In Si-PV, n-type silicon nanowires are grown by chemical vapor deposition (CVD) via the Au catalyzed the bottom-up method on ptype silicon substrate.

These nanostructures help to increase performance and have antireflection properties by multiple reflections. It is expected to enhance light absorption and short circuit current. ${ }^{55-57}$ Cabarrocas et al. reported ultra-thin Sn layers that were evaporated on top of the substrate and applied $\mathrm{H}_{2}$ plasma treatment at $180^{\circ} \mathrm{C}$ to form Sn catalyst droplet. $^{59}$ Droplets act as catalyst to facilitate the growth of $\mathrm{Si}$ nanowires at total gas pressure of $600 \mathrm{mTorr}$ and RF power density of $50 \mathrm{~mW} / \mathrm{cm}^{2}$. Si nanowires which have a diameter of around $80 \mathrm{~nm}$ and enhanced strong light trapping capability more than $90 \%$ within $1.7 \mu \mathrm{m}$ $\mathrm{Si}$ in 300 to $700 \mathrm{~nm}$ of wavelength range. Moreover, the density of $\mathrm{Si}$ nanowires played an important role in light absorption because higher light absorption was detected as density of Si nanowires increases. ${ }^{58,59}$ Falk et al. demonstrated the sputtered Au layer which has thickness of $2 \mathrm{~nm}$ and heated the sample to $700^{\circ} \mathrm{C}$ for making catalytic droplet. As a result of this experiment, nanowires were fabricated with the mean diameter of $80 \mathrm{~nm}$, and these nanowires demonstrated more than $90 \%$ enhancement of light absorption within $1.5 \mu \mathrm{m} \mathrm{Si}$ in the wavelength region below $1000 \mathrm{~nm}$. In the case of a planar sample, the absorption drops to as low as $55 \%$ at $400 \mathrm{~nm}$ and $70 \%$ in the $600 \mathrm{~nm}$ wavelength region. ${ }^{60}$ Christiansen et al. reported their experiment that the nanowires grown on glass substrate have a length of 3-6 $\mu \mathrm{m}$ and diameter in range of $20-100 \mathrm{~nm}$. A strong broadband optical absorption can be observed in the relatively thin $\mathrm{Si}$ nanowire films. This phenomenon can be attributed to the significant reduction of the reflectance and the strong light trapping of the nanowires. ${ }^{61}$

\subsection{Nanopillar and Nanocone Arrays (Top-Down Method)}

The nanocone and nanopillar structures can be customized through the whole process. Zhu et al. recently published a paper concerned with nanostructures for $\mathrm{PV}^{17}$ The PV device performances of fabricated nanopillar and nanocone arrays were compared with that of the thin film a-Si:H PV device. The surface of thin film a-Si:H looks very smooth and shiny since most of the absorbed light is reflected.

On the other hand, the nanopillar and nanocone arrays have darker

Table 1 Summary of nanostructure fabrication and light absorption rate

\begin{tabular}{|c|c|c|c|c|}
\hline Author & $\begin{array}{c}\text { Published } \\
\text { date }\end{array}$ & $\begin{array}{l}\text { Process } \\
\text { method }\end{array}$ & Structure & Absorption \\
\hline $\begin{array}{c}\text { Cabarrocas } \\
\text { et al. }{ }^{59}\end{array}$ & 2013 & VLS & Nanowire & $\begin{array}{c}90 \% \text { within } \\
1.7 \mu \mathrm{m} \mathrm{Si}\end{array}$ \\
\hline Falk et al. ${ }^{60}$ & 2013 & VLS & Nanowire & $\begin{array}{c}90 \% \text { within } \\
1.5 \mu \mathrm{m} \mathrm{Si}\end{array}$ \\
\hline Zhu et al. ${ }^{17}$ & 2009 & RIE & Nanocone & $\begin{array}{c}90 \% \text { within } \\
1.0 \mu \mathrm{m} \mathrm{Si}\end{array}$ \\
\hline Zhu et al. ${ }^{17}$ & 2009 & RIE & Nanopillar & $\begin{array}{c}70 \% \text { within } \\
1.0 \mu \mathrm{m} \mathrm{Si}\end{array}$ \\
\hline Lal et al. ${ }^{62}$ & 2010 & Litho-graphy & $\begin{array}{l}\text { Nano-conical- } \\
\text { frustum }\end{array}$ & $\begin{array}{c}99 \% \text { within } \\
3.5 \mu \mathrm{m} \mathrm{Si}\end{array}$ \\
\hline Najar et al. ${ }^{63}$ & 2012 & $\begin{array}{c}\text { Mac- } \\
\text { Etching }\end{array}$ & Nanowire & $\begin{array}{c}99.9 \% \text { within } \\
31 \mu \mathrm{m} \mathrm{Si}\end{array}$ \\
\hline
\end{tabular}

surfaces. Especially, the nanocone arrays look almost black and the surface was very rough. For a quantative measurement, they performed absolute hemispherical measurement with an integrating sphere. In addition, the Maxwell equation with rigorous coupled-wave analysis was used for numerical comparison. The results show that $90 \%$ of light absorption within $1.0 \mu \mathrm{m} \mathrm{Si}$ for nanocone arrays which is the highest among three samples. Nanopillar arrays and thin film have $70 \%$ and $45 \%$ within $1.0 \mu \mathrm{m} \mathrm{Si}$, respectively. When the incidence angle is increasing, the light absorption of all three samples is decreasing, but the nano-cone arrays still have the highest values due to the characteristic cone shaped structure. Lal et al. fabricated an ordered $\mathrm{Si}$ nano-conical-frustum array structure by lithography techniques. The feature of nanocone like nanostructure is height of $3.5 \mu \mathrm{m}$ and top radius of $170 \mathrm{~nm}$, bottom radius of $400 \mathrm{~nm}$. Due to the higher light trapping ability of conical structure, absorption of the ordered Si arrays is exhibited about $99 \%$ over wavelengths $400-1100 \mathrm{~nm}^{62}$

In the case of the MacEtching, nanostructure for photovoltaic using Si nanowire was reported by Najar et al. ${ }^{63}$ This paper reported photovoltaic device with porous Si nanowire created by MacEtching. After thorough cleaning, Si wafer was dipped into aqueous $\mathrm{HF} / \mathrm{AgNO}_{3}$ solution for $\mathrm{Ag}$ deposition which affects the $\mathrm{Si}$ with porous surface and it was rinsed with distilled water to remove residual silver ions. Then $\mathrm{Si}$ wafer was transferred to the $\mathrm{HF}-\mathrm{H}_{2} \mathrm{O}_{2}$ solution bath for etching process. The fabricated porous Si nanowire with length of $31 \mu \mathrm{m}$ and diameter of $\sim 150 \mathrm{~nm}$ was reported as less than $0.1 \%$ of reflectance for various wavelengths and indicated that the fabricated nanowire is able to drastically decrease the reflectance for enhancing solar cell performance. All of the earlier published results of enhancing absorption rates in Si-PV as suggested in this paper are well organized in Table 1.

\section{Conclusions}

Recent approaches and results of fabricating various nanostructures for solar cells are discussed in this report. To overcome bulky thickness problem of crystalline $\mathrm{Si}$, thin film $\mathrm{Si}$ based solar cell such as a-Si:H was considered. However, the mismatch of the length between minority carrier diffusion length and sufficient absorption thickness has caused other issues lowering the performance. To compensate this gap, various nanostructures were employed in solar cell fabrication. Two most popularly used nanostructure fabrication methods are introduced and categorized in this paper; VLS, SLS as a bottom-up and RIE, MacEtching as a top-down method. VLS and SLS grow the silicon structure beneath the catalyst on Si substrate at the nucleation in liquidsolid interface. These methods are capable of conformal growth of $\mathrm{Si}$ nanowires in large-area platform, while having no chance to control the growing direction due to non-uniform orientation and difficulty in fabricating ordered array structure. RIE is employed for the Si based substrate with a masking material to have a certain cone shaped structure which comes from the diffusion limit of the bottom structure. This difference of etching rate caused by masking material affects the etching of Si substrate with different geometry of structures. Therefore remained Si structures can be nanostructures with nanowire and tapered geometry. MacEtching is a wet etching method having intrinsic and anisotropic characteristic. This method utilizes the different etching rate 
of catalyst/substrate interface and the substrate itself in a certain solution mixture. Like the RIE, template-based structures are considered as a mask for MacEtching in order to obtain highly ordered arrays of nanowires. Therefore, the fabricated nanostructures are employing to enhance light absorption locating the nanostructure in surface of the solar cells. Thus, many researches have reported repeatedly that such nanostructures significantly contribute to increase light absorption in various wavelength regions.

\section{ACKNOWLEDGEMENT}

Y.B.K. and S.W.H. is grateful to the National Research Foundation (NRF) of the Korean Ministry of Education, Science, and Technology (MEST) (Grant No. 2012R1A1A1014689) for its financial support.

\section{REFERENCES}

1. Tsakalakos, L., "Nanostructures for Photovoltaics," Mater. Sci. Eng. R., Vol. 62, No. 6, pp. 175-189, 2008.

2. Ji, S., Hwang, Y. S., Park, T., Lee, Y., Paek, J., and et al., "Graphite Foil Based Assembled Bipolar Plates for Polymer Electrolyte Fuel Cells,” Int. J. Precis. Eng. Manuf., Vol. 13, No. 12, pp. 2183-2186, 2012.

3. Chang. I., Lee, M. H., Lee, J., Kim, Y., and Cha, S. W., “AirBreathing Flexible Polydimethylsiloxane (PDMS)-Based Fuel Cell," Int. J. Precis. Eng. Manuf., Vol. 14, No. 3, pp. 501-504, 2013

4. Kim, T., Lee, J., Kim, D., and Park, H., "Ultra-Short Laser Patterning of Thin-Film CIGS Solar Cells through Glass Substrate," Int. J. Precis. Eng. Manuf., Vol. 14, No. 8, pp. 1287-1292, 2013

5. Kim, M., Chun, D., Choi, J., Lee, J., Kim, K., and et al., "Room Temperature Deposition of $\mathrm{TiO}_{2}$ using Nano Particle Deposition System (NPDS): Application to Dye-Sensitized Solar Cell (DSSC)," Int. J. Precis. Eng. Manuf., Vol. 12, No. 4, pp. 749-752, 2011

6. Becquerel, E., "La lumi_ere : Ses Causes et Ses E_ets," tome second, Paper No. 122, 1867.

7. Chapin, D. M., Fuller, C. S., and Pearson, G. L., "A New Silicon p-n Junction Photocell for Converting Solar Radiation into Electrical Power,” J. Appl. Phys., Vol. 25, No. 5, pp. 676-677, 1954.

8. Shockley, W. and Queisser, H. J., "Detailed Balance Limit of Efficiency of p-n Junction Solar Cells," J. Appl. Phys., Vol. 32, No. 3, pp. 510-519, 1961.

9. Catalano, A., "Polycrystalline Thin-Film Technologies: Status and Prospects,” Sol. Energy Mat. Sol. C., Vol. 41-42, pp. 205-217, 1996.

10. Shah, A. V., Platz, R., and Keppner, H., "Thin-Film Silicon Solar Cells: A Review and Selected Trends," Sol. Energy Mat. Sol. C., Vol. 38, No. 1-4, pp. 501-520, 1995.

11. Herzinger, C. M., Johs, B., McGahan, W. A., Woollam, J. A., and Paulson, W., "Ellipsometric Determination of Optical Constants for
Silicon and Thermally Grown Silicon Dioxide via a Multi-Sample, Multi-Wavelength, Multi-Angle Investigation,” J. Appl. Phys., Vol. 83, No. 6, pp. 3323-3336, 1998.

12. Werner, J. H., Bergmann, R., and Brendel, R., "The Challenge of Crystalline Thin Film Silicon Solar Cells," in: Festkörperprobleme 34, Helbig, R.(Eds.), Springer Berlin Heidelberg, pp. 115-146, 1994.

13. Han, S. E. and Chen, G., "Optical Absorption Enhancement in Silicon Nanohole Arrays for Solar Photovoltaics," Nano Lett., Vol. 10, No. 3, pp. 1012-1015, 2010.

14. Chopra, K. L., Paulson, P. D., and Dutta, V., "Thin-Film Solar Cells: an Overview," Progress in Photovoltaics: Research and Applications, Vol. 12, No. 2-3, pp. 69-92, 2004.

15. Okano, T., "A New Multi-Electrode Evaporator for Refractory Metals and Its Application to Getter Pumps,” Jpn. J. Appl. Phys., Vol. 20, pp. 213-219, 1981.

16. Müller, J., Rech, B., Springer, J., and Vanecek, M., “TCO and Light Trapping in Silicon Thin Film Solar Cells," Solar Energy, Vol. 77, No. 6, pp. 917-930, 2004.

17. Zhu, J., Yu, Z., Burkhard, G. F., Hsu, C. M., Connor, S. T., and et al., "Optical Absorption Enhancement in Amorphous Silicon Nanowire and Nanocone Arrays,” Nano Lett, Vol. 9, No. 1, pp. 279-282, 2009.

18. Kayes, B. M., Atwater, H. A., and Lewis, N. S., "Comparison of the Device Physics Principles of Planar and Radial P-N Junction Nanorod Solar Cells,” J. Appl. Phys., Vol. 97, No. 11, Paper No. 4302-11, 2005.

19. Li, J., Yu, H., Wong, S. M., Zhang, G., Sun, X., and et al., "Si Nanopillar Array Optimization on Si Thin Films for Solar Energy Harvesting," Appl. Phys. Lett., Vol. 95, No. 3, Paper No. 3102, 2009.

20. Hu, L. and Chen, G., "Analysis of Optical Absorption in Silicon Nanowire Arrays for Photovoltaic Applications," Nano Lett, Vol. 7, No. 11, pp. 3249-3252, 2007.

21. Wagner, R. S. and Ellis, W. C., "Vapor-Liquid-Solid Mechanism of Single Crystal Growth,” Appl. Phys. Lett., Vol. 4, pp. 89-90, 1964.

22. Duan, X. and Lieber, C. M., "General Synthesis of Compound Semiconductor Nanowires," Adv. Mater., Vol. 12, No. 4, pp. 298302, 2000 .

23. Wu, Y., Yan, H., and Yang, P., "Semiconductor Nanowire Array: Potential Substrates for Photocatalysis and Photovoltaics," Top. Catal., Vol. 19, No. 2, pp. 197-202, 2002.

24. Lew, K. K., Pan, L., Dickey, E. C., and Redwing, J. M., "VaporLiquid-Solid Growth of Silicon-Germanium Nanowires," Adv. Mater., Vol. 15, No. 24, pp. 2073-2076, 2003.

25. Mårtensson, T., Borgström, M., Seifert, W., Ohlsson, B. J., and Samuelson, L., "Fabrication of Individually Seeded Nanowire Arrays by Vapour-Liquid-Solid Growth," Nanotechnology, Vol. 14, No. 12, pp. 1255-1258, 2003. 
26. Sandulova, A. V., Bogoyavlenskii, P. S., and Dronyuk, M. I., "Preparation and Some Properties of Whisker and Needle-Shaped Single Crystals of Germanium, Silicon and Their Solid Solutions," Sov. Phys. Sol. State, Vol. 5, pp. 1883, 1964.

27. Wagner, R. S., Ellis, W. C., Jackson, K. A., and Arnold, S. M., "Study of the Filamentary Growth of Silicon Crystals from the Vapor,” J. Appl. Phys., Vol. 35, No. 10, pp. 2993-3000, 1964.

28. Greiner, E. S., Gutowski, J. A., and Ellis, W. C., "Preparation of Silicon Ribbons,” J. Appl. Phys., Vol. 32, No. 11, pp. 2489-2490, 1961.

29. Zhang, Y. F., Tang, Y. H., Wang, N., Yu, D. P., Lee, C. S., and et al., "Silicon Nanowires Prepared by Laser Ablation at High Temperature,” Appl. Phys. Lett., Vol. 72, No. 15, pp. 1835-1837, 1998.

30. Zhou, G. W., Zhang, Z., Bai, Z. G., Feng, S. Q., and Yu, D. P., "Transmission Electron Microscopy Study of Si Nanowires," Appl. Phys. Lett., Vol. 73, No. 5, pp. 677-679, 1998.

31. Pan, Z. W., Dai, Z. R., Xu, L., Lee, S. T., and Wang, Z. L., "Temperature-Controlled Growth of Silicon-Based Nanostructures by Thermal Evaporation of SiO Powders," J. Phys. Chem. B, Vol. 105, No. 13, pp. 2507-2514, 2001.

32. Schmidt, V., Wittemann, J. V., Senz, S., and Gösele, U., "Silicon Nanowires: a Review on Aspects of their Growth and their Electrical Properties," Adv. Mater., Vol. 21, No. 25-26, pp. 26812702, 2009.

33. Xia, Y., Yang, P., Sun, Y., Wu, Y., Mayers, B., and et al., "OneDimensional Nanostructures: Synthesis, Characterization, and Applications,” Adv. Mater., Vol. 15, No. 5, pp. 353-389, 2003.

34. Huang, Y., Duan, X., Wei, Q., and Lieber, C. M., "Directed Assembly of One-Dimensional Nanostructures into Functional Networks," Science, Vol. 291, No. 5504, pp. 630-633, 2001.

35. He, R., Gao, D., Fan, R., Hochbaum, A. I., Carraro, C., Maboudian, R., and Yang, P., "Si Nanowire Bridges in Microtrenches: Integration of Growth into Device Fabrication," Adv. Mater., Vol. 17, No. 17, pp. 2098-2102, 2005.

36. Zhu, J., Peng, H., Chan, C. K., Jarausch, K., Zhang, X. F., and Cui, Y., "Hyperbranched Lead Selenide Nanowire Networks," Nano Lett, Vol. 7, No. 4, pp. 1095-1099, 2007.

37. Gudiksen, M. S., Lauhon, L. J., Wang, J., Smith, D. C., and Leiber, C. M., "Growth of Nanowire Superlattice Structures for Nanoscale Photonics and Electronics," Nature, Vol. 415, No. 6872, pp. 617620, 2002.

38. Lauhon, L. J., Gudiksen, M. S., Wang, D., and Lieber, C. M., "Epitaxial Core-Shell and Core-Multishell Nanowire Heterostructures," Nature, Vol. 420, No. 6911, pp. 57-61, 2002.

39. Cui, Y., Lauhon, L. J., Gudiksen, M. S., Wang, J., and Lieber, C. M., "Diameter-Controlled Synthesis of Single-Crystal Silicon Nanowires," Appl. Phys. Lett., Vol. 78, No. 15, pp. 2214-2216,
2001.

40. Lee, J. H. and Geer, R. E., "Templated Si-Based Nanowires via Solid-Liquidsolid (SLS) and Vapor-Liquid-Solid (VLS) Growth: Novel Growth Mode, Synthesis, Morphology Control, Characteristics, and Electrical Transport," in: Cutting Edge Nanotechnology, Vasileska, D., (Ed.), InTech, 2010.

41. Trentler, T. J., Hickman, K. M., Goel, S. C., Viano, A. M., Gibbons, P. C., and Buhro, W. E., "Solution-Liquid-SolidGrowth of Crystalline Ill-V Semiconductors: An Analogy to Vapor-LiquidSolid Growth,” Science, Vol. 270, No. 5243, pp. 1791-1794, 1995.

42. Holmes, J. D., Johnston, K. P., Doty, R. C., and Korgel, B. A., "Control of Thickness and Orientation of Solution-Grown Silicon Nanowires," Science, Vol. 287, No. 5457, pp. 1471-1473, 2000.

43. Seeger, K., and Palmer, R. E., "Fabrication of Ordered Arrays of Silicon Nanopillars," J. Phys. D: Applied Physics, Vol. 32, No. 24, pp. 129-132, 1999.

44. Peng, K., Zhang, M., Lu, A., Wong, N. B., Zhang, R., and Lee, S. T., "Ordered Silicon Nanowire Arrays via Nanosphere Lithography and Metal-Induced Etching," Appl. Phys. Lett., Vol. 90, No. 16, Paper No. 163123-3, 2007.

45. Winters, H. F., "The Role of Chemisorption in Plasma Etching," J. Appl. Phys., Vol. 49, No. 10, pp. 5165-5170, 1978.

46. Lo, T. C. and Huang, H. C., "Anisotropic Etching of Deep Trench for Silicon Monolithic Microwave Integrated Circuit," Electron. Lett., Vol. 29, No. 25, pp. 2202-2203, 1993.

47. Hsu, C. M., Connor, S. T., Tang, M. X., and Cui, Y., "Wafer-Scale Silicon Nanopillars and Nanocones by Langmuir-Blodgett Assembly and Etching," Appl. Phys. Lett., Vol. 93, No. 13, Paper No. 3109, 2008.

48. Li, X. and Bohn, P. W., "Metal-Assisted Chemical Etching in HF/ H2O2 Produces Porous Silicon,” Appl. Phys. Lett., Vol. 77, No. 16, pp. 2572-2574, 2000.

49. Huang, Z., Geyer, N., Werner, P., de Boor, J., and Gösele, U., "Metal-Assisted Chemical Etching of Silicon: A Review," Adv. Mater., Vol. 23, No. 2, pp. 285-308, 2011.

50. Li, X., "Metal Assisted Chemical Etching for High Aspect Ratio Nanostructures: A Review of Characteristics and Applications in Photovoltaics," Curr. Opin. Solid. St. M., Vol. 16, No. 2, pp. 71-81, 2012.

51. Chartier, C., Bastide, S., and Lévy-Clément, C., "Metal-assisted Chemical Etching of Silicon in HF-H2O2," Electrochim. Acta., Vol. 53, No. 17, pp. 5509-5516, 2008.

52. Huang, Z., Fang, H., and Zhu, J., "Fabrication of Silicon Nanowire Arrays with Controlled Diameter, Length, and Density," Adv. Mater., Vol. 19, No. 5, pp. 744-748, 2007.

53. Huang, Z., Zhang, X., Reiche, M., Liu, L., Lee, W., Shimizu, T., Senz, S., and Gosele, U., "Extended Arrays of Vertically Aligned Sub-10 nm Diameter [100] Si Nanowires by Metal-Assisted 
Chemical Etching,” Nano Lett, Vol. 8, No. 9, pp. 3046-3051, 2008.

54. Perraud, S., Poncet, S., Noël, S., Levis, M., Faucherand, P., and et al., "Full Process for Integrating Silicon Nanowire Arrays into Solar Cells," Sol. Energ. Mat. Sol. C., Vol. 93, No. 9, pp. 1568-1571, 2009.

55. Yung Kuo, C., Gau, C., and Tong Dai, B., "Photovoltaic Characteristics of Silicon Nanowire Arrays Synthesized by VaporLiquid-Solid Process," Sol. Energ. Mat. Sol. C., Vol. 95, No. 1, pp. 154-157, 2011.

56. Gunawan, O. and Guha, S., "Characteristics of Vapor-Liquid-Solid Grown Silicon Nanowire Solar Cells,” Sol. Energ. Mat. Sol. C., Vol. 93, No. 8, pp. 1388-1393, 2009.

57. Kempa, T. J., Day, R. W., Kim, S. K., Park, H. G., and Lieber, C. M., "Semiconductor Nanowires: A Platform for Exploring Limits and Concepts for Nano-Enabled Solar Cells," Energy Environ. Sci., Vol. 6, No. 3, pp. 719-733, 2013.

58. Yu, L., Rigutti, L., Tchernycheva, M., Misra, S., Foldyna, M., Picardi, G., and Roca i Cabarrocas, P., “Assessing Individual Radial Junction Solar Cells over Millions on VLS-Grown Silicon Nanowires," Nanotechnology, Vol. 24, No. 27, Paper No. 275401, 2013.

59. Misra, S., Yu, L., Foldyna, M., and Roca i Cabarrocas, P., "High Efficiency and Stable Hydrogenated Amorphous Silicon Radial Junction Solar Cells Built on VLS-Grown Silicon Nanowires," Sol. Energ. Mat. Sol. C., Vol. 118, pp. 90-95, 2013.

60. Eisenhawer, B., Sill, I., and Falk, F., "Radial Heteroemitter Solar Cells Based on VLS Grown Silicon Nanowires," Phys. Stat. solidi (a), Vol. 210, No. 4, pp. 695-700, 2013.

61. Stelzner, T., Pietsch, M., Andrä, G., Falk, F., Ose, E., and Christiansen, S., "Silicon Nanowire-Based Solar Cells," Nanotechnology, Vol. 19, No. 29, Paper No. 295203, 2008.

62. Lu, Y. and Lal, A., "High-Efficiency Ordered Silicon Nano-ConicalFrustum Array Solar Cells by Self-Powered Parallel Electron Lithography," Nano Lett., Vol. 10, No. 11, pp. 4651-4656, 2010.

63. Najar, A., Charrier, J., Pirasteh, P., and Sougrat, R., "Ultra-Low Reflection Porous Silicon Nanowires for Solar Cell Applications," Optics Express, Vol. 20, No. 15, pp. 16861-16870, 2012.

64. Zhang. M. L., Peng, K. Q., Fan, X., Jie, J. S., Zhang, R. Q., and et al., "Preparation of Lagre-Area Uniform Silicon Nanowires Arrays through Metal-Assisted Chemical Etching," J. Phys. Chem., Vol. 112, No. 12, pp. 4444-4450, 2008 